\title{
Model Pembelajaran Interaktif SPLDV dengan Aplikasi Rumah Belajar
}

\author{
Yuliza Putri Utami ${ }^{\left.1^{*}\right)}$, Putri Sukma Dewi ${ }^{2}$ \\ ${ }^{1,2}$ Universitas Teknokrat Indonesia \\ *) lizaputriutamilaa@gmail.com
}

\begin{abstract}
Abstrak
Aplikasi rumah belajar (ARB) dibuat secara khusus untuk memudahkan guru dan siswa mendapatkan materi kepentingan mengajar siswa. Portal ini dapat di akses melalui https://belajar.kemdikbud.go.id/ .Berbeda pada situs internet lainnya, ARB lebih menunjukkan sisi kreativitas antara pengguna yaitu pendidik dan peserta didik. ARB dibuat khusus oleh kemdikbud agar guru dan siswa dapat mengakses materi belajar, melakukan simulasi interaktif serta komunikasi dan interaksi antar pendidik dan ARB bertujuan untuk menambah pengetahuan, keterampilan serta meningkatkan komunikasi dan interaksi antara guru dan siswa. Metode yang digunakan adalah studi literatur dimana penulis mencari referensi teori yang relafan sesuai kasus atau permasalahan yang ditemukan dan melakukan percobaan ARB fitur kelas digital dengan 5 siswa SMP. Hasil percobaan tersebut menunjukkan bahwa sebagai sumber belajar untuk memperoleh konten dan sarana pembelajaran kelas digital bisa didapatkan melalui pemanfaatan ARB. Dengan kata lain, sebagai fasilitas terjadinya pembelajaran online antara peserta didik dan pendidik kapan saja dan di mana saja. Ini bisa diterapkan agar meningkatnya hasil belajar peserta didik yang dapat meningkatkan kualitas pembelajaran. Oleh karena itu,disarankan kepada siswa dan guru untuk dapat memanfaatkanAplikasi Rumah Belajar.
\end{abstract}

Kata kunci : kelas digital, pembelajaran interaktif, rumah belajar.

\begin{abstract}
The Aplikasi Rumah Belajar (ARB) was created specifically to make it easier for teachers and students to get material for students' teaching interests. This portal can be accessed via https://belajar.kemdikbud.go.id/. Different from other internet sites, ARB shows more creativity between users, namely educators and students. ARB is made specifically by the Ministry of Education and Culture so that teachers and students can access learning material, conduct interactive simulations and communication and interaction between educators and ARB aims to increase knowledge, skills and improve communication and interaction between teachers and students. The method used is a literature study in which the writer seeks relevant reference theory according to the case or problem found and conducts an ARB digital class experiment with 5 junior high school students. The results of these experiments indicate that as a learning resource to obtain content and digital classroom learning tools can be obtained through the use of ARB. In other words, as a facility of online learning between students and educators anytime and anywhere. This can be applied to improve student learning outcomes that can improve the quality of learning. Therefore, it is recommended to students and teachers to be able to utilize the Aplikasi Rumah Belajar.
\end{abstract}

Keyword : digital class, interactive learning, learning house.

\section{Pendahuluan}

Teknologi informasi merupakan perkembangan sistem informasi dengan menggabungkan antara teknologi komputer dengan telekomunikasi (Baharudin, 2010). Tuntutan global menuntut dunia pendidikan senantiasa menyesuaikan perkembangan 
teknologi terhadap usaha dalam peningkatan mutu pendidikan, terutama penyesuaian penggunaannya bagi dunia pendidikan khususnya dalam proses pembelajaran dengan membangun infrastruktur hardware, jaringan internet, dan lain-lainnya, yang dilakukan dalam usaha memenuhi kebutuhan akan metode pembelajaran yang lebih efektif.

Pembelajaran interaktif dapat diselenggarakan dalam berbagai model dengan memanfaatkan teknologi. "Pembelajaran dapat dilaksanakan melalui audio atau radio, video atau TV, multimedia,serta pembelajaran dengan menggunakan media komputer dan internet" (Rosyid,2010). Pembelajaran dengan menggunakan media komputer dan internet merupakan salah satu alternatif yang sangat berpotensial, di mana kebutuhan pendidikan yang telah mendunia terkait adanya perluasan akses yang tidak terbatasi.

Berdasarkan laman situs unbk.web tahun 2018 menyebutkan bahwa "Meskipun model pembelajaran interaktif dapat menjadi media pendidikan yang sangat efektif. Namun terdapat juga kontra dalam pembelajaran interaktif, jika siswa tidak mampu menggunakan teknologi mereka akan kehilangan minat belajar, maka partisipasi dalam program online tidak akan adil untuk semua siswa dalam pembelajaranonline".

Aplikasi Rumah Belajar telah dibuat dan dikembangkan oleh Pustekkom Kemdikbud sejak tahun 2011 sebagai salah satu portal pembelajaran berbasis web, yang berisi berbagai layanan pembelajaran (Utari, 2018). Dengan alamat URL https://belajar.kemdikbud.go.id/, Rumah Belajar yang merupakan portal pembelajaran resmi miliki Kementerian Pendidikan dan Kebudayaan bisa diakses.

Terdapat berbagai macam fitur yang dapat dimanfaatkan untuk kegiatan pembelajaran tersedia di ARB. Terdapat beberapa fitur utama didalamnya, seperti Sumber Belajar, Kelas Digital, Bank Soal, Laboratorium Maya, Modul Digital, Peta Budaya, Wahana Jelajah Angkasa, Pengembangan Keprofesian Berkelanjutan dan Buku Sekolah Elektroknik (BSE). Selain fitur utama, (Ai, 2018) menyatakan bahwa "konten-konten dan media pembelajaran yang tersedia di Rumah Belajar tersebut dapat dimanfaatkan oleh pendidik, peserta didik, dan masyarakat dalam belajar".

Manfaat dari Aplikasi Rumah Belajar sebagai media pembelajaran menyenangkan adalah memungkinkan terjadinya interaksi langsung antara guru, peserta didik dan sumber belajar (Nurul, 2019). Selain itu, proses pembelajaran dapat dilanjutkan di luar jam pembelajaran dengan mudah yaitu peserta didik tinggal membuka kembali materi pembelajaran yang baru disampaikan pada saat jam pembelajaran. Menurut Imanuddin, dkk (2014), "konten pembelajaran Matematika, Bahasa Inggris, IPA, IPS dan Bahasa 
Indonesia akan lebih menarik dibandingkan dengan media pembelajaran berupa buku, karena bersifat interaktif dilengkapi dengan teks, audio, visual, animasi, simulasi dalam penyampaian materi sehingga informasi pembelajaran disampaikan lebih menyenangkan, menarik, mudah dimengerti dan jelas".

Pengaruh teknologi khususnya ARB dapat diperoleh secara gratis selama 24 jam mulai dari jenjang pendidikan SD, SMP, SMA atau SMK. Rumah Belajar diharapkan dapat membantu siswa meningkatkan hasilsecara efektif dan Aplikasi ini juga diharapkan dapat digunakan siswa dalam menerima materi pembelajarankhususnya Matematika.Berdasarkan hal tersebut maka peneliti melakukan sebuah penelitian untuk mengembangkan sebuah media pembelajaran.

\section{Metode Penelitian}

Metode penelitian yang digunakan dalam penelitian ini adalah studi literatur. Peneliti melakukan sebuah penelitian untuk melihat bagaimana proses pembelajaran dengan menggunakan aplikasi rumah belajar dan mengamati ARB dalam konsep belajar mengajar berbasis online atau e-learning.

Penelitian ini melibatkan lima siswa SMP dengan teknik pengumpulan data dan informasinya melalui studi literatur dimana peneliti mencari referensi teori yang relefan sesuai kasus atau permasalahan yang ditemukan dan melakukan percobaan ARB fitur kelas digital dengan 5 siswa SMP. Peneliti melakukan pelatihan kreativitas menjadi materi tutor untuk diajarkan kepada siswa di ARB. Percobaan dilakukan dengan tujuan untuk mengetahui keberhasilan program kreativitas ARB, apakah program tersebut sesuai dengan tujuan yang telah ditetapkan sebelumnya (Yahudi, 2017). Pengumpulan data dilakukandengan mengkaji hasil-hasil penelitian sejenisyang sudah ada sebelumnya. Analisis data dilakukan secara deskriptif dan Penelitian ini berusaha mendeskripsikan ARB dalam pembelajaran online.

\section{Hasil dan Pembahasan}

Portal rumah belajar merupakan media belajar berbasis internet (online) yang dibuat secara khusus oleh pusat teknologi, komunikasi kementerian pendidikan dan kebudayaan. Portal pembelajaran menyediakan bahan belajar serta fasilitas komunikasi yang mendukung interaksi antar komunitas. Rumah Belajar hadir sebagai bentuk inovasi pembelajaran di era industri 4.0 yang dapat dimanfaatkan oleh siswa dan guru Pendidikan Sekolah Dasar (SD), Sekolah Menengah Pertama (SMP), Sekolah Menengah Atas atau 
Kejuruan (SMA dan SMK) dengan menggunakan Rumah Belajar, kita dapat belajar di mana saja, kapan saja dengan siapa saja.

\section{Mari belajar dan bergabung dengan pengguna lainnya di Rumah Belajar

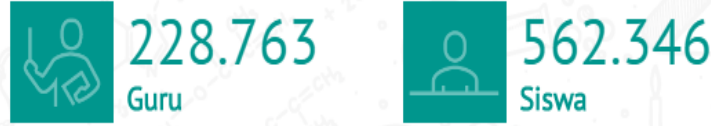

Gambar 1. Pengguna Aplikasi Rumah Belajar.

Jumlah pengguna ARB yang aktif dalam mengajar dan belajar terakses untuk para guru dan siswa kini bakal makin mudah dan menyenangkan, tidak hanya menyenangkan tapi juga dapat mendukung sumber belajar siswa dan mempermudah akses pendidikan untuk siswa, aplikasi rumah belajar (ARB) ini dibuat secara khusus sesuai dengan kebutuhan pendidikan dan diharapkanpengguna ARB terus meningkat dari waktu ke waktu sehingga guru dan siswa mampu menjawab persoalan baik itu materi atau soal media pembelajaran berbasis online dan icon atau fitur ARB dapat dilihat pada Gambar 2.

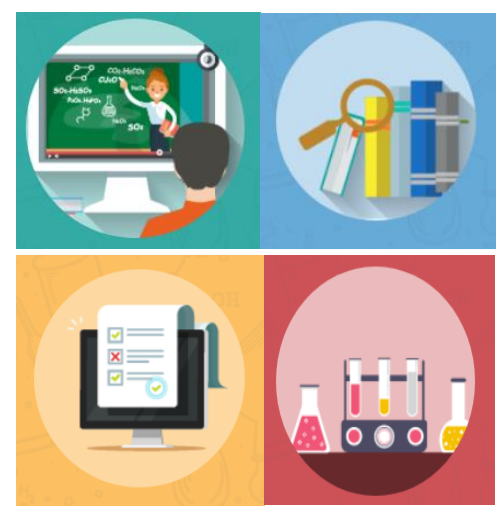

Gambar 2. Icon Kelas Digital, Sumber Belajar, Bank Soal, dan Laboraturium Maya.

\section{Icon Portal Rumah Belajar}

\section{Kelas Digital}

Kelas Digital adalah fasilitas dalam proses pembelajaran tanpa tatap muka antara guru dan siswa. Dengan fitur ini, guru dapat memberikan bahan ajar yang dapat diakses dan dibagikan oleh siswa dalam bentuk digital kapan saja dan di mana saja. Pendidik dan peserta didik dapat mengikuti pembelajaran virtual dengan pendidik chat, video, audio, desktop sharing. Kelas digital dapat menuntut pembelajaran interaktif untuk mendorong keterampilan peserta didik dan kelas digital ini merupakan sarana pembelajaran online bagi 
peserta didik dan pendidik serta dapat diakses kapan saja dan dimana saja. Gambar 3 berikut merupakan rincian cara login dan alur penggunaan portal rumah belajar di kelas digital.

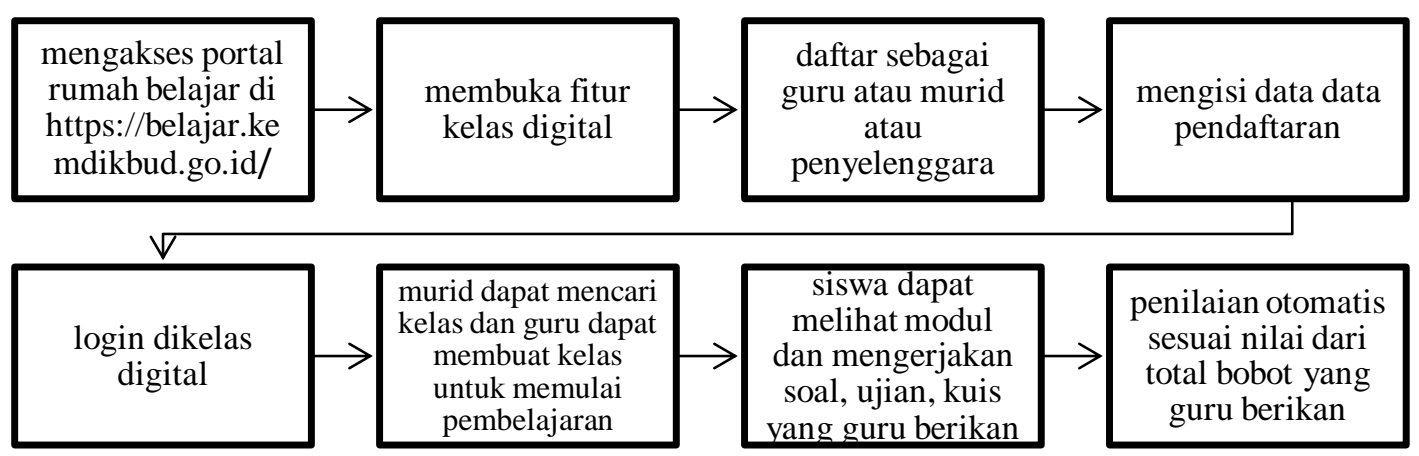

\section{Sumber Belajar}

Gambar 3. Alur ARB di kelas digital.

Sumber belajar adalah Fitur yang menyajikan materi ajar bagi siswa dan guru berdasarkan kurikulum. Materi ajar disajikan secara terstruktur dengan tampilan yang menarik dalam bentuk gambar, video, animasi, simulasi, evaluasi, dan permainan. Selain menyediakan berbagai materi pengetahuan jenjang pendidikan PAUD, SD, SMP, SMA dan SMK juga menyediakan sarana evaluasi belajar secara online sesuai dengan tuntutan perkembangan TIK.

\section{Bank Soal}

Bank soal adalah fitur kumpulan soal dan materi evaluasi siswa yang dikelompokkan berdasarkan topik ajar. Tersedia juga berbagai akses soal latihan, ulangan, dan ujian. Bank soal Dapat diakses sesuai yang diinginkan. Mata Pelajaran yang tersedia di Bank Soal adalah Matematika, IPA, IPS, Bahasa Indonesia dan Bahasa Inggis. Bank soal digunakan untuk membantu guru dan siswa. Bank soal sudah memperhatikan tingkat kesulitan yang secara teratur serta memberikan wawasan dalam pendidikan. Pemanfaatannya dapat dilakukan melalui kelas danproses pengembangan bahan soal guru dapat memberikan suasana belajar yang lebih interaktif.

\section{Laboraturium Maya}

Laboratorium Maya adalah Fitur simulasi praktikum laboratorium yang disajikan secara interaktif dan menarik, dikemas bersama lembar kerja siswa dan teori praktikum. Laboratorium maya dapat dimanfaatkan secara online maupun offline. Hal ini dilakukan secara elektronik diprogram dalam komputer untuk mensimulasikan percobaan nyata di 
dalam laboratorium maya yang sudah dilengkapi dengan contoh lembar kerja siswa, referensi materi, dan panduan pemanfaatan.

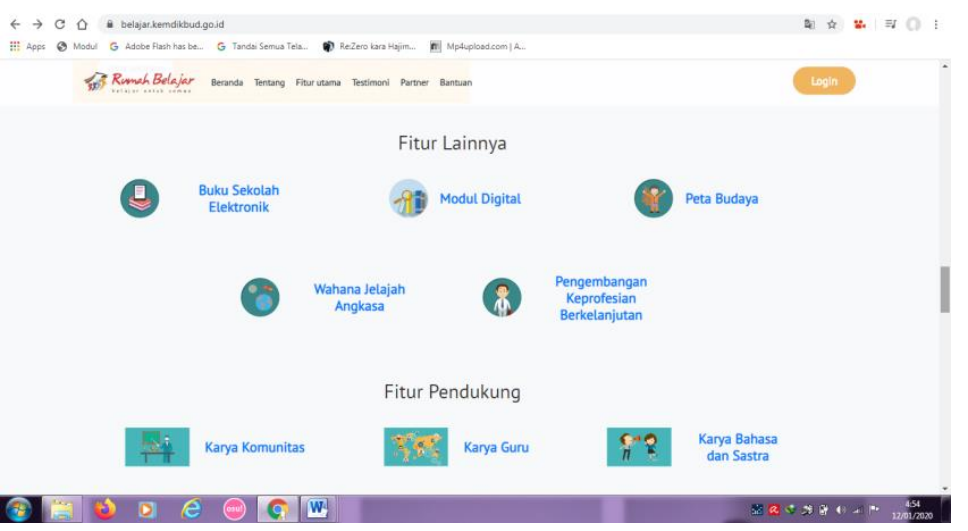

Gambar 4. Fitur Lainnya (BSE,Modul Digital, Peta Budaya,wahana jelajah angsa, PKB) dan Fitur Pendukung (Karya Komunitas, Karya Guru, Karya Bahasa dan Sastra).

Berdasarkan fitur pada gambar 4 aplikasi rumah belajar ternyata terdapat banyak fitur, diharapkan guru dan siswa dapat mencoba dan diterapkan ke lingkungan sekitarnya agar paham media pembelajaran berbasis online 4.0 sehingga media pembelajaran dapat dikembangkan untuk kreativitas pendidik maupun peserta didik sesuai kebutuhan dan konten pembelajaran.

\section{Sebagai Sumber Belajar.}

Melalui pemanfaatan sumber belajar ARB, hasil aktivitas belajar dan memotivasi peserta didik untuk melakukan diskusi, mengerjakan tugas, dan lain-lain dapat meningkat. Oleh karena itu, dengan memanfaatkan sumber belajar pada ARB ini peserta didik dituntut untuk aktif dalam menyimpulkan dan menganalisis (Mulyadi, 2015). Berdasarkan hal tersebut, pemanfaatan sumber belajar ini dapat meningkatkan hasil pembelajaran yaitu dapat memahami dan mengaplikasikan konsep.

Akhirnya, dengan adanya bahan belajar di fitur sumber belajar, pendidik dan peserta didik mendapatkan berbagai fasilitas dan sumber belajar yang berkualitas. Bahwa wawasannya peserta didik dapat memanfaatkannya untuk belajar mandiri dikelas. Sedangkan bagi guru, pemanfaatan Sumber Belajar ARB dapat digunakan sebagai pengembangan bahan ajar, media pembelajaran di kelas. Selain itu, guru dapat memanfaatkannya pada saat jam kosong (guru tidak hadir), dan sebagai sarana media pembelajaran online atau e-learning (Martiningsih, 2017). 


\section{Sarana Pembelajaran Kelas Digital.}

Salah satu fitur utama Portal Rumah Belajar adalah fitur Kelas Digital . Fitur Kelas digital ini merupakan sarana untuk pembelajaran online yang dikembangkan secara khusus untuk memfasilitasi terjadinya pembelajaran virtual antara peserta didik dan guru kapan saja dan di mana saja. Kelas digital yaitu strategi pembelajaran aktif, dan berpusat pada peserta didik. Penerapan pembelajaran digital merupakan paradigma positif dan alat baru yang potensial untuk melakukan revolusi dengan memperluas akses terhadap pendidikan (Dykman, 2008). Selain itu,penerapan pembelajaran digital ini dapat meningkatkan konsep belajar, adaptasi, dan penerapan bahan belajar.

\section{Sosialisasi dan Percobaan Terhadap Siswa dengan Aplikasi Rumah Belajar.}

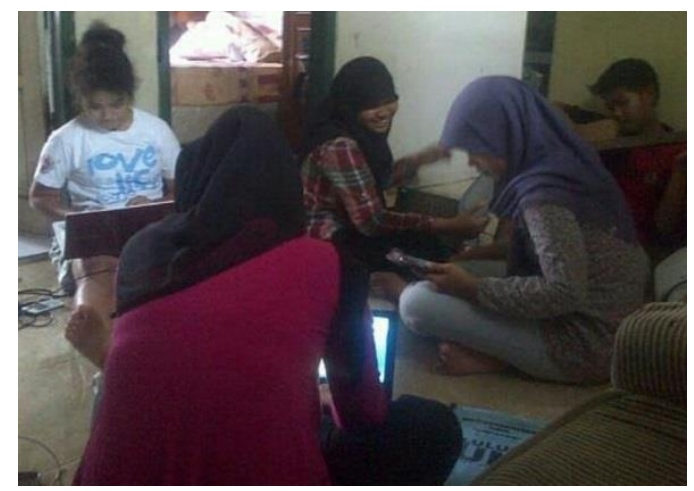

Gambar 5. Sosialisasi dan percobaan terhadap siswa dengan Aplikasi Rumah Belajar.

Rumah Belajar merupakan portal pembelajaran yang diharapkan dapat membantu pendidik dan peserta didik yang ingin mendapatkan materi pembelajaran berbasis online, dapat dilihat pada Gambar 5. Maka dari itu peneliti melibatkan 5 siswa SMP untuk percobaan ARB terutama memanfaatkan fitur kelas digital. Secara keseluruhan ternyata dengan adanya ARB dapat menjadi media pengembangan dan peningkatan kompetensi siswa, karenake lima siswa dengan mudah dapat mengakses aplikasi rumah belajar dan mereka berpendapat "Setelah kamimencoba menggunakan aplikasi rumah belajar ternyata mudah dan dapat menjadi motivasi belajar kami“.

Hal ini sesuai dengan hasil tentang pengaruh media interaktif berbasis media pembelajaran online terhadap ARB dan terjadinya peningkatan minat belajar peserta didik pada topik sistem persamaan linear dua variabel. Dengan demikian, pembelajaran dengan memanfaatkan fitur Kelas digital pada ARB terbukti mampu meningkatkan minat belajar peserta didik. 


\section{Simpulan dan Saran}

Berdasarkan hasil penelitian ini diperoleh kesimpulan bahwa model pembelajaran interaktif SPLDV dengan menggunakan aplikasi rumah belajar terhadap siswa terutama siswa menengah pertama (SMP) adalah pembelajaran lebih menarik, karena rumah belajar kemdikbud menyajikan materi-materi pembelajaran berbasis teknologi yang membuat siswa tertarik dan bermanfaat untuk pembelajaran. Rumah belajar juga sangat konsisten untuk di gunakan pelajar baik itu SD, SMP, SMA karena rumah belajar bisa berbasis online dan dapat dikerjakan dirumah. Penulis mengarapkan peserta didik dan guru dapat memanfaatkan ARB dengan baik dan disarankan penelitian lainnya untuk melakukan uji coba pada sampel yang lebih banyak.

\section{Referensi}

Attridge, Inglis M. 2013.Advanced Mathematical Study and The Development of Conditional Reasoning Skills. Orxon: Plos one.

Afgani, Darmawijoyo. 2008. Pengembangan Media Website Pembelajaran Materi Program Linear untuk Siswa Sekolah Menengah Atas. Yogyakarta : Jurnal Pendidikan Matematika.

Baharudin, R. 2010. Keefektifan Media Belajar Berbasis Teknologi Informasi dan Komunikasi. Jakarta : Universitas Negeri Jakarta.

Harun. 2015. Efektifitas Penggunaan Teknologi Informasi dan Komunikasi dalam Pembelajaran Pendidikan Agama Islam. Potensia: Jurnal Kependidikan Islam.

Kusna, Rosyid. 2010. Pendidikan Kewarganegaraan Kelas VI. Jakarta: Intan Pariwara.

Kirsi. 2014. Interctive Learning in the Classroom-not a Competitor but a Partner for eLearning. Finland: Helsinki University of Technology.

Kadir, Abdul. 2013. Pengenalan Sistem Informasi. Yogyakarta: Universitas Negeri Yogyakarta.

Nurhayati, Ai Sri. 2012. Pedoman Pemanfaatan Rumah Belajar. Jakarta: Pustekkom Kemdikbud.

Notodirojo. 2015. Teknologi Internet Mobile Seminar Nasional Internet Mobile. Yogyakarta: Program Studi Sistem Informasi Fakultas Teknologi Informasi.

Riwayadi. 2013. Pemanfaatan Perkembangan Teknologi Informasi dan Komunikasi untuk Kemajuan Pendidikan di Indonesia. Jakarta: Imadiklus.

Yaniawati. 2017. Kualitas Workshop E-learning untuk Guru Matematika di Bandung. Bandung: Universitas Pasundan.

Yahudi. 2017. Pemberdayaan Masyarakat melalui Program Kreativitas di Rumah Belajar Modern Desa Bangunharjo Sewon Bantul. Yogyakarta: Universitas Negeri Yogyakarta.

http://unbk.web.id/pro-dan-kontra-pendidikan-online-untuk-warga-dunia/ http://www.thegeniusworks.com/2017/01/future-education-young-everyone-taughttogether 